\title{
Tuberculosis Case Notification and Treatment Outcomes in West Gojjam Zone, Northwest Ethiopia: A Five-Year Retrospective Study
}

\author{
Senedu B. Gebreegziabher1,2*, Solomon A. Yimer1,2,3,4, Gunnar A. Bjune ${ }^{2}$ \\ ${ }^{1}$ Amhara Regional State Health Bureau, Bahir Dar, Ethiopia \\ ${ }^{2}$ Department of Community Medicine, Institute of Health and Society, University of Oslo, Oslo, Norway \\ ${ }^{3}$ Oslo University Hospital, Oslo, Norway \\ ${ }^{4}$ Department of Bacteriology and Immunology, Division of Infectious Disease Control, Norwegian Institute of \\ Public Health, Oslo, Norway \\ Email: "sinidu_bekele@yahoo.com,yimsolo@yahoo.com,g.a.bjune@medisin.uio.no
}

Received 8 January 2016; accepted 18 March 2016; published 21 March 2016

Copyright (C) 2016 by authors and Scientific Research Publishing Inc.

This work is licensed under the Creative Commons Attribution International License (CC BY).

http://creativecommons.org/licenses/by/4.0/

(c) (i) Open Access

\section{Abstract}

Introduction: Tuberculosis (TB) is a major public health concern in Ethiopia. Analysis of TB case notification and treatment outcomes is crucial to understand the TB control program performance. The current study was carried out to assess trends of TB case notifications, treatment success rate and factors associated with unsuccessful treatment outcome among TB patients in West Gojjam Zone of Amhara Region, Ethiopia. Method: A retrospective cohort study was conducted in West Gojjam Zone. Demographic and clinical data were reviewed for all TB patients registered between July 2007 and June 2012 at 30 randomly selected public health facilities of the study zone. In addition, annual case notification reports of the study zone were used to analyze trends in TB case notifications. Logistic regression analysis was used to assess the association between potential predictor variables and unsuccessful treatment outcomes. Results: Tuberculosis case notification for all forms of TB decreased from 203/100,000 population in 2007 to $155 / 100,000$ population in 2012. Among patients whose treatment outcomes were evaluated, $94.4 \%$ were successfully treated, $0.3 \%$ had treatment failure, $1.5 \%$ defaulted and $3.7 \%$ died. In multivariate analysis, the odds of unsuccessful treatment outcome was higher among retreatment cases than new cases (adjusted OR, 3.44; 95\% CI: 1.92, 6.19). HIV co-infected cases were more likely to have unsuccessful treatment outcome compared to HIV negatives (adjusted OR, 2.68; 95\% CI: 1.92, 3.72). Conclusion: Tuberculosis case notification rates showed a decreasing trend between 2007 and 2012 . The

\footnotetext{
"Corresponding author.
} 
treatment success rate exceeded the $90 \%$ treatment success rate target as set by the WHO. Special attention is required for patients with high risk of unsuccessful treatment outcome. Therefore, retreatment cases, and HIV positive cases need strict follow up throughout their treatment period.

\author{
Keywords
}

Tuberculosis, Case Notification, Treatment Outcome, Ethiopia

\title{
1. Introduction
}

Tuberculosis (TB) is a major public health concern in the developing world. According to World Health Organization (WHO) report in 2014, there were 9.6 million new TB cases and 1.5 million deaths from TB worldwide [1]. The 22 high TB burden countries collectively account for $80 \%$ of TB cases.

Ethiopia is among the 22 high-TB burden countries in the world. The prevalence and incidence of TB in the country is estimated at 200/100,000 population and 207/100,000 population, respectively [1]. Based on the national population based TB prevalence survey conducted in 2010/2011 the prevalence of smear-positive and all forms of TB was estimated at 108/100,000 population and 240/100,000 population, respectively [2]. Cognizant of the huge burden of TB in the country, the Government of Ethiopia has incorporated TB control as one of the priority health program packages in the country's Health Sector Development Program [3]. However, TB still remains a major public health problem in Ethiopia.

In Ethiopia, the directly observed treatment short-course (DOTS) strategy was started as a pilot in Arsi and Bale zones, Oromia Region in 1992 [4]. It was then subsequently scaled up nationwide and a 100\% geographical and $92 \%$ health facility coverage were achieved [2]. Nonetheless, previous studies conducted in different regions of Ethiopia showed that the passive case finding approach, where TB patients self-report to health care facilities leaves significant number of undiagnosed TB cases in the community [5]-[9].

For effective TB control, it is very important to detect cases as early as possible and to ensure that those diagnosed complete their treatment and get cured [10]. TB case notification and treatment success rates are used to measure the TB control program performance [1]. Monitoring the treatment outcome and understanding of reasons for unsuccessful treatment outcome are also essential in order to improve treatment outcome [11]. Studies previously conducted in Ethiopia assessed treatment outcome and various results were reported. The treatment success rates of $89.1 \%, 82.6 \%, 55.7 \%, 85.5 \%$, and $29 \%$ were observed in Northern Ethiopia [12], Addis Ababa [13], Western Ethiopia [14] and North West Ethiopia [15] [16], respectively. The observed difference in treatment success rate across these studies may be related to variations in DOTS performance [12], length of the study periods and the sample size used. It may also be due to inclusion of transferred out TB cases in the analysis where the actual treatment outcome of this group is not known [17]. Some of the independent predictors for unsuccessful treatment outcome previously reported were: patient's age over 55 years, retreatment cases, HIV sero positivity, being male, and long distance from home to health facilities [12] [18] [19].

In Amhara Region where this study was conducted, DOTS strategy has been introduced since 1996 and its geographic coverage reached 100\% of the region in 2009 [20]. Despite the high TB burden and DOTS coverage in the study region however, no study has so far assessed trends in case notification and treatment success rates at a larger scale. Thus, the current study was carried out to assess trends of TB case notifications, treatment success rate and factors associated with unsuccessful treatment outcome among TB patients in West Gojjam Zone of Amhara Region, Ethiopia.

\section{Methods}

\subsection{Study Setting}

The study area, West Gojjam Zone, is one of the ten zones in the Amhara Region of Ethiopia. The total population is estimated at 2,382,497 [21], and more than $90 \%$ of the population reside in rural areas. Agriculture is the main source of livelihood for the community. Administratively, West Gojjam Zone is divided into 13 rural districts and five town administrations. One government hospital, 90 health centers, 76 private health facilities 
(hospitals and higher clinics) and 363 government health posts are actively providing health service to the population in the study zone. Of these, one government hospital, 73 government health centers and six private health institutions had TB diagnostic and treatment facilities. Two hundred and seventy six health posts in the study zone were serving as treatment centers for DOTS. A health post is the lowest level health facility and is staffed by two female health extension workers (HEWs). HEWs play an important role in identifying and referring TB suspects to the next level of health care i.e. health centers for TB diagnosis and initiation of treatment. Health posts are not equipped with TB diagnostic tools. TB cases are diagnosed and treated based on the national TB control guideline [4]. Sputum smear microscopy is the basic TB diagnostic method used at health centers. Thus all extra pulmonary TB (EPTB) and clinically suspected smear-negative pulmonary TB (PTB-) cases must be referred to hospitals and private clinics for chest radiography and other necessary investigations for TB. During the study period, the treatment regimen given contained an intensive phase of daily chemotherapy with (2RHZE) rifampicin, isoniazid, pyrazinamide, and ethambutol for two months, followed by a continuous phase treatment with (6EH) ethambutol and isoniazid for six months [4]. Since 2011, the continuous phase treatment has been shortened into four months which contain (4RH) isonized and rifampicin. TB patients in the study zone also seek traditional health care including self-treatment and holy water from the Orthodox Church [22]. Public transport and horseback riding are the main means of transport in the study area.

\subsection{Sampling Procedure}

Simple random sampling method was used to select the study sites. First we obtained the list of all public health facilities providing TB diagnosing and treatment services in West Gojjam Zone. Of these 29 health centers were selected randomly and a hospital selected purposely. All TB patients registered between July 2007 and June 2012 were included. All health facilities included in the study had standardized unit TB registers.

\subsection{Definition of Variables}

Case definition and treatment outcome were defined based on the standard definitions of the National TB and leprosy control program guideline of Ethiopia for the diagnosis and treatment of TB cases [4].

Smear-positive pulmonary TB $(\mathrm{PTB}+)$ : a patient with at least two initial sputum smear examinations positive for acid-fast bacilli (AFB) by direct microscopy, or one initial smear examination positive for AFB by direct microscopy and culture positive, or one initial smear examination positive for AFB by direct microscope and radiographic abnormalities consistent with active TB as determined by a clinician.

Smear-negative pulmonary TB (PTB-): a patient with symptoms suggestive of TB with at least three AFB negative sputum smear examinations, radiographic abnormalities consistent with active pulmonary TB, no response to a course of broad spectrum antibiotics and a decision by a clinician to treat with a full course of ant-TB chemotherapy.

Extra pulmonary TB (EPTB): A patient has TB in organs other than the lungs, proven by one culture-positive specimen from an extra-pulmonary site or histo-pathological evidence from a biopsy, or based on strong clinical evidence consistent with active EPTB and the decision by a physician to treat with a full course of anti-TB therapy.

Retreatment cases include the following three sub-categories: treatment failure, relapse and default cases. "Treatment after failure" is defined as a patient who started on retreatment after the previous treatment has failed. A patient previously treated for TB who returns to treatment having previously defaulted is referred to as "default". A "relapse" case is defined as a patient who previously was declared cured or treatment completed and is diagnosed with bacteriologically-positive (sputum smear or culture).

A new case of TB is a patient who has never had treatment for TB or who had taken anti-TB drugs for less than one month.

The treatment outcomes were categorized as cured, treatment completed, defaulted, treatment failure and died. A patient is considered "cured" when sputum smear examination is bacteriologically negative in the last month of treatment and on at least one previous occasion. If a patient completed treatment without having a negative bacteriological result in the last month of treatment and on at least one previous occasion, the patient is declared as "treatment completed". If a patient interrupted his treatment for 8 or more consecutive weeks after he/she had been on treatment for at least 4 weeks, the patient is considered as a "defaulter".

Treatment failure is defined as a patient who remains or becomes again smear-positive at the end of 5 months 
or later during treatment. A patient is declared "dead” if he/she died for any reason during the course of treatment. Patients are considered as "transferred out" if they are transferred to another health facility and the treatment outcome is not known.

Successfully treated: the sum of cured and treatment completed cases.

Thus in this study we dichotomized the treatment outcome into: successful treatment outcome (cured and treatment completed) and unsuccessful treatment outcome (died, treatment failure and defaulted). The independent variables used were age, sex, residence, type of TB, category of TB and HIV status.

\subsection{Study Design and Data Collection}

This was facility based retrospective cohort study. We reviewed the profile of all TB patients registered between July 2007 and June 2012 at 30 public health facilities of the study zone. Demographic and clinical data were reviewed from the unit TB registers of each health facility by trained health officers and nurses. Age, sex, residence, TB type, TB category, HIV status, follow-up sputum examination result and treatment outcome were reviewed for each patient. The overall activities were supervised by the principal investigator and other supervisors. Due to resource and time limitations we had, we used case notification annual reports of all districts for each study year in the study zone to achieve our first objective.

\subsection{Statistical Analysis}

Data were analyzed using Statistical Package for the Social Sciences (SPSS) IBM Version 20 (SPSS Inc. Chicago, IL, USA) and were cleaned for errors before the analysis. Ten percent of the data were double entered in order to assure quality of the data. Case notification rates per 100,000 population were calculated by taking each year's population estimate as a denominator and notified cases as numerator. The study zone population for each year was projected based on estimates of Central Statistics Authority in Ethiopia [21]. Descriptive analysis such as frequency, mean and standard deviation were computed. Bivariate analysis was first performed to examine the association of each independent variable on unsuccessful treatment outcome. Thereafter, multivariate logistic regression analysis was used to measure the independent effects of each predictor variable on unsuccessful treatment outcomes. Variables with a P-value of $<0.2$ in the bivariate analysis were included in the multivariate model. A P-value of $<0.05$ was considered statistically significant. Odds ratios with 95\% confidence interval were used to assess the strength of association between variables.

\subsection{Ethical Approval}

The Regional Committee for Medical Research Ethics (REK Øst) in Oslo, Norway and the National Research Ethics Review Committee (NRERC) in Addis Ababa, Ethiopia, were approved this study. Permission was obtained from respective local administrations. The record review from the unit TB registers was done anonymously without mentioning the patients’ name.

\section{Results}

\subsection{General Characteristics of Study Subjects}

The treatment records of 15,140 TB patients registered between July, 2007 and June, 2012 at 30 DOTS sites of the study zone were reviewed. Of these were $50.7 \%$ males and $48.1 \%$ females yielding a male to female ratio of 1.1:1. Type of sex was not documented for $1.2 \%$ of the cases. The mean age was 29.8 years with \pm 15.0 year's standard deviation (SD). Most, 90.6\% of the TB cases were newly diagnosed. More than half (51.2\%) of TB patients were EPTB cases. Seven hundred and sixteen (10.5\%) of the TB patients were co-infected with HIV (Table 1). Among TB/HIV co-infected patients, 249 (33.1\%), 327 (43.4\%) and 177 (23.5\%) were EPTB, PTBand PTB+ cases, respectively.

\subsection{Trends in TB Case Notification}

The trend in case notification was analyzed using data that included all cases reported during the study period in the study zone. Accordingly, between July 2007 and June 2012, a total of 19726 new and 285 retreatment cases of all forms of TB were reported from West Gojjam Zone. Case notification rate for newly diagnosed TB cases 
Table 1. General characteristics of the study subjects in West Gojjam Zone July 2007-June 2012 (N = 15,140).

\begin{tabular}{|c|c|c|}
\hline Characteristics & Number (N) & Percent (\%) \\
\hline \multicolumn{3}{|l|}{ Age group (years) } \\
\hline$\leq 14$ & 1750 & 11.6 \\
\hline $15-24$ & 4315 & 28.5 \\
\hline $25-49$ & 6916 & 45.7 \\
\hline$\geq 50$ & 1963 & 13.0 \\
\hline Not documented & 196 & 1.3 \\
\hline \multicolumn{3}{|l|}{ Sex } \\
\hline Male & 7675 & 50.7 \\
\hline Female & 7281 & 48.1 \\
\hline Not documented & 184 & 1.2 \\
\hline \multicolumn{3}{|l|}{ Residence } \\
\hline Urban & 4266 & 28.2 \\
\hline Rural & 9491 & 62.7 \\
\hline Not documented & 1383 & 9.1 \\
\hline \multicolumn{3}{|l|}{ TB type } \\
\hline Smear-positive pulmonary & 2918 & 19.3 \\
\hline Smear-negative pulmonary & 4322 & 28.5 \\
\hline Extra pulmonary & 7754 & 51.2 \\
\hline Not documented & 146 & 1.0 \\
\hline \multicolumn{3}{|l|}{ Patient category } \\
\hline New & 13,710 & 90.6 \\
\hline Transfer in & 261 & 1.7 \\
\hline *Other & 140 & 0.9 \\
\hline Relapse & 165 & 1.1 \\
\hline Treatment after default & 10 & 0.1 \\
\hline Treatment after failure & 29 & 0.2 \\
\hline Not documented & 825 & 5.4 \\
\hline \multicolumn{3}{|l|}{ HIV serostatus } \\
\hline Positive & 716 & 10.5 \\
\hline Negative & 6086 & 89.5 \\
\hline
\end{tabular}

*Other: a patient who does not fit in any of the categories listed above; the HIV status is among TB patients who were tested for HIV during the study period.

of all forms increased from 203 per 100,000 population in July 2007-June 2008 to 204 per 100,000 population in July 2008-June 2009, then consistently decreased the following years and reached at 155 per 100,000 population in July 2011-June 2012 (Table 2). 


\subsection{Treatment Follow-Up}

Among 2918 PTB+ patients, 1961 (67.2\%) had sputum smear examination at two months of treatment. Of these, 117 (5.9\%) remained smear-positive. The sputum examination result at the end of two months of follow-up period was not documented for 32.8\% of patients. At the end of five months of treatment, 1576 (54\%) PTB+ cases had sputum smear examination and 29 (1.8\%) remained smear positive. At seven months, 1466 (50.2\%) had sputum examination and 19 (1.3\%) patients remained smear-positive.

\subsection{Treatment Outcomes}

Among 15,140 TB patients registered over the study period, 2945 (19.5\%) were transferred out and 2101 (13.9\%) did not have documented treatment outcomes. For this analysis, we excluded all transferred out cases and patients with un documented treatment outcome from the treatment outcome analysis. Accordingly, of the 10094 TB patients who had documented treatment outcome, 9528 (94.4\%) were successfully treated, 154 (1.5\%) were defaulted, 377 (3.7\%) died, 35 (0.3\%) had treatment failure (Table 3). The average treatment success rate of new PTB+ cases was $93 \%$. Of these, $72.1 \%$ of PTB + patients were cured. The remaining $20.9 \%$ of PTB + patients completed their treatment but the sputum examination result at the end of treatment was not known. New TB patients had higher treatment success rate (94.6\%) compared to retreatment cases $(84.2 \%)$ (Table 4).

Table 2. Trends of all forms of TB case notifications in West Gojjam Zone July 2007-June 2012.

\begin{tabular}{cccc}
\hline Year & New TB cases notified & Zonal population & $\begin{array}{c}\text { TB case notification per 100,000 } \\
\text { population per year }\end{array}$ \\
\hline July 2007-June 2008 & 4358 & $2,143,564$ & 203 \\
July 2008-June 2009 & 4445 & $2,181,311$ & 204 \\
July 2009-June 2010 & 3678 & $2,220,932$ & 166 \\
July 2010-June 2011 & 3676 & $2,260,279$ & 163 \\
July 2011-June 2012 & 3569 & $2,299,484$ & 155 \\
\hline
\end{tabular}

Zonal population projected from the 2007 population and housing census, CSA [21]. The five year average TB case notification for all forms of TB was 178 per 100,000 population/year.

Table 3. Trends of treatment success rate across the years for all types of TB in West Gojjam Zone July 2007-June 2012.

\begin{tabular}{|c|c|c|c|c|c|c|}
\hline \multirow[b]{2}{*}{$\begin{array}{l}\text { Treatment } \\
\text { outcomes }\end{array}$} & \multicolumn{5}{|c|}{ Year } & \multirow[b]{2}{*}{$\begin{array}{l}\text { Total } \\
\text { n (\%) }\end{array}$} \\
\hline & $\begin{array}{c}\text { July } 2007- \\
\text { June } 2008 \\
\text { n (\%) }\end{array}$ & $\begin{array}{c}\text { July 2008- } \\
\text { June } 2009 \\
\text { n (\%) }\end{array}$ & $\begin{array}{c}\text { July 2009- } \\
\text { June } 2010 \\
\text { n (\%) }\end{array}$ & $\begin{array}{c}\text { July } 2010- \\
\text { June } 2011 \\
\text { n (\%) }\end{array}$ & $\begin{array}{c}\text { July 2011- } \\
\text { June } 2012 \\
\text { n (\%) }\end{array}$ & \\
\hline Treatment success & 1995 (93.4) & $1866(94.6)$ & 2219 (95.3) & 1897 (94.3) & $1551(94.2)$ & $9528(94.4)$ \\
\hline Death & $96(4.5)$ & $66(3.3)$ & $75(3.2)$ & $80(4.0)$ & $60(3.6)$ & 377 (3.7) \\
\hline Default & 40 (1.9) & $36(1.8)$ & $30(1.3)$ & $26(1.3)$ & $22(1.3)$ & $154(1.5)$ \\
\hline Failure & $6(0.3)$ & $4(0.2)$ & $4(0.2)$ & $8(0.4)$ & $13(0.8)$ & $35(0.3)$ \\
\hline
\end{tabular}

Table 4. Treatment outcomes of TB patients by category and forms of TB in West Gojjam Zone July 2007-June 2012.

\begin{tabular}{|c|c|c|c|c|c|}
\hline Characteristics & $\begin{array}{c}\text { Successfully treated } \\
\text { n (\%) }\end{array}$ & $\begin{array}{c}\text { Default } \\
\text { n (\%) }\end{array}$ & $\begin{array}{l}\text { Death } \\
\text { n (\%) }\end{array}$ & $\begin{array}{l}\text { Failure } \\
\text { n (\%) }\end{array}$ & $\begin{array}{l}\text { Total } \\
\text { n (\%) }\end{array}$ \\
\hline $\mathrm{PTB}+$ & $1923(92.3)$ & $26(1.2)$ & $100(4.8)$ & $35(1.7)$ & 2084 \\
\hline PTB- & 2663 (92.3) & $59(2.0)$ & $163(5.6)$ & $0(0)$ & 2885 \\
\hline ЕРТВ & 4905 (96.4) & $69(1.4)$ & $113(2.2)$ & $0(0)$ & 5087 \\
\hline New TB cases & $8739(94.6)$ & $132(1.4)$ & $346(3.7)$ & $25(0.3)$ & 9242 \\
\hline Retreatment TB cases & $123(84.2)$ & $5(3.4)$ & $9(6.2)$ & $9(6.2)$ & 146 \\
\hline
\end{tabular}


Re-treatment cases had higher treatment failure rate $(6.2 \%)$ compared to new TB cases $(0.3 \%)(\mathrm{P}<0.001)$. The defaulter rate among retreatment cases was higher (3.4\%) compared to new TB patients $(1.4 \%)(\mathrm{P}<0.001)$. The death rate among retreatment TB patients was higher $(6.2 \%)$ compared to new TB cases $(3.7 \%)(\mathrm{P}<0.001)$.

\subsection{Trend in Treatment Success Rate}

The trend in treatment success rate of all TB patients steadily increased from 93.4\% in July 2007-June 2008 to 95.3\% in July 2009-June 2010 then decreased to 94.2\% in July 2011-June 2012. Death rate steadily decreased from 4.5\% in July 2007-June 2008 to 3.2\% in July 2009-June 2010 then increased to 4\% in July 2010-June 2011 again decreased into 3.6\% in July 2011-June 2012 (Table 3). The death rate was increased across age groups from 23 (2.1\%), 61 (2.1\%), 96 (3.7\%), 70 (4.6\%), 60 (5.5\%), 43 (8.0\%) and 18 (6.4\%), in the age groups 0 - 14, 15 - 24, 25 - 34, 35 - 44, 45 - 54, 55 - 64 and $\geq 65$ year, respectively.

\subsection{Factors Associated with Unsuccessful Treatment Outcome}

Retreatment cases were more likely to have unsuccessful treatment outcome compared to new cases (adjusted OR, 3.44; 95\% CI: 1.92, 6.19). HIV co-infected patients were at increased risk of unsuccessful treatment outcome than HIV negatives (adjusted OR, 2.68; 95\% CI: 1.92, 3.72). Patients in the age groups of 0 - 14, 15 - 24, and 25 - 49 were less likely to have unsuccessful treatment outcome compared to patients above 50 years of age. Similarly, EPTB cases were less likely to have unfavorable treatment outcome compared to PTB+ patients (adjusted OR 0.57; 95\% CI: 0.40, 0.82) (Table 5).

Table 5. Socio demographic and clinical factors associated with unsuccessful treatment outcome among TB patients in West Gojjam Zone July 2007-June 2012.

\begin{tabular}{|c|c|c|c|c|}
\hline Characteristics & $\mathrm{N}$ & $\begin{array}{c}\text { Unsuccessful } \\
\text { treatment outcomes } \\
\text { (n \%) }\end{array}$ & COR (95\% CI) & AOR (95\% CI) \\
\hline \multicolumn{5}{|l|}{ Sex } \\
\hline Male & 5057 & $324(6.4)$ & $1.37(1.15,1.63)^{*}$ & $1.27(0.98,1.64)$ \\
\hline Female & 4970 & $236(4.7)$ & 1 & 1 \\
\hline \multicolumn{5}{|l|}{ Age group } \\
\hline $0-14$ & 1094 & $36(3.3)$ & $0.33(0.23,0.49)^{*}$ & $0.20(0.10,0.40)^{* *}$ \\
\hline $15-24$ & 2873 & 111 (3.9) & $0.39(0.29,0.51)^{*}$ & $0.36(0.25,0.53)^{* *}$ \\
\hline $25-49$ & 4683 & $286(6.1)$ & $0.63(0.51,0.79)^{*}$ & $0.45(0.33,0.63)^{* *}$ \\
\hline$\geq 50$ & 1444 & $133(9.2)$ & 1 & 1 \\
\hline \multicolumn{5}{|l|}{ Residence } \\
\hline Urban & 3080 & $218(7.1)$ & $1.46(1.22,1.74)^{*}$ & $0.835(0.64,1.09)$ \\
\hline Rural & 6240 & $310(5.0)$ & 1 & 1 \\
\hline \multicolumn{5}{|l|}{ Type of ТВ } \\
\hline PTB- & 2885 & $222(7.7)$ & $0.99(0.81,1.23)$ & $1.18(0.84,1.65)$ \\
\hline ЕРТВ & 5087 & $182(3.6)$ & $0.44(0.36,0.55)^{*}$ & $0.57(0.40,0.82)^{* *}$ \\
\hline PTB + & 2084 & $161(7.7)$ & 1 & 1 \\
\hline \multicolumn{5}{|l|}{ Category } \\
\hline Retreatment & 146 & $23(15.7)$ & $3.25(2.06,5.11)^{*}$ & $3.44(1.92,6.19)^{* *}$ \\
\hline New & 9242 & $503(5.4)$ & 1 & 1 \\
\hline \multicolumn{5}{|l|}{ HIV sero-status } \\
\hline Reactive & 589 & 82 (13.9) & $3.42(2.61,4.48)^{*}$ & $2.68(1.92,3.72)^{* *}$ \\
\hline Non-reactive & 4732 & 214 (4.5) & 1 & 1 \\
\hline
\end{tabular}

$\mathrm{N}=$ number of observation; ${ }^{*}$ Crude odds ratio; ${ }^{* *}$ Adjusted odds ratio; COR = Crude odds ratio, AOR = Adjusted odds ratio, $\mathrm{CI}=\mathrm{Confidence} \mathrm{interval.}$ 


\section{Discussion}

In this study, we found that the case notification rate for all forms of TB increased from 203/100,000 population in July 2007-June 2008 to 204/100,000 population in July 2008-June 2009. This might be related to increased DOTS sites expansion in Amhara Region which significantly improved access to TB diagnosis and treatment [20]. It may also be due to increased TB incidence fueled by the powerful interaction between HIV and TB [23]. The proportion of TB/HIV co-infection in our study was 10.5\%. The Amhara Region where the study zone is found is one of the regions in Ethiopia with high HIV burden [24]. After the second year of the study period, the TB case notification rate steadily decreased and reached 155/100,000 population at the end of the study period (2012). A reduction in diagnostic delay and the detection of backlog of undetected TB cases after the expansion of DOTS sites might have contributed for the consistent TB case notification decline observed in this study. It may also be explained partly by increased anti-retroviral therapy (ART) site expansion in Amhara Region over the study period [25] [26]. ART site expanation has an effect in the decline of TB cases notifications [27] [28]. However, the decline trend should be interpreted cautiously given the limited availability of culture and histopathology facilities to diagnose PTB- and EPTB cases in the study area in particular and Ethiopia at large.

In this study, the overall treatment success rate for all TB patients was $94.4 \%$ and is higher than the $90 \%$ global target as set by WHO [29]. The study result is also higher compared to previous treatment success rate reports of 87.8\% and 85.6\% in North West Ethiopia [15] [30], 55.7\% in Western Ethiopia [14], 82.7\% in Addis Ababa [13], and 91.1\% in Northern Ethiopia [31]. Another study from North West Ethiopia showed a treatment success rate of $94.8 \%$ which is comparable with our study result [32].

A consistently high treatment success rate was observed over the study period. This may be linked to an improved access to TB diagnostic and treatment services as a result of subsequent DOTS sites expansion. The health extention workers contribution in identifying and referring suspected TB cases, defaulter tracing and awareness creation in the community could also be a possible explanation.

The average death rate in our study was 3.7\%. This is lower compared to previous study reports of $10.5 \%$ in Northwest Ethiopia [16], and 7.4\% Central Ethiopia [17]. The death rate steadily decreased over the study period except in July 2010 to June 2011 where it increased from 3.2\% to 4\%. However, it subsequently decreased again the following years. The conserted efforts in the implementation of TB/HIV collaborative activities in Ethiopia [33] might be the possible explanation for the decrease in death rate. On the other hand, the death rate steadily increased among patients above the age of 55 years. This is in agreement with previous study findings in Ethiopia [12] [16] [18] [34]. Increasing age has been reported to be a risk factor for death due to increasing co-morbidity and physiological deterioration [15] [35]. Thus early diagnosis of TB and close monitoring of treatment in old age patients is crucial.

The overall defaulter rate was $1.5 \%$, which is lower than previous defaulter rates of $3.5 \%, 18.3 \%$, $3.5 \%$, and 8.5\% reported from North West Ethiopia [15] [16], Northern Ethiopia [12], and from Central Ethiopia [17], respectively. The very low defaulter rate observed in our study may be related to improved TB diagnostic and treatment services access and the regular communication and collaboration between health posts and health centers in defaulter tracing. The use of DOTS contact person to closely monitor and trace patients who default [30] may also be a contributing factor.

The overall treatment failure rate was $0.3 \%$ and is comparable with previous study findings of $0.2 \%-0.5 \%$ from Ethiopia [13] [16] [17], but lower than the 3.7\% and 7.8\% failure rates reported from Northern Ethiopia [12] and Central Ethiopia, respectively [17]. However, the treatment failure rate increased from $0.4 \%$ to $0.8 \%$ between July 2010 and June 2012 in our study.

The treatment failure and death rates among retreatment cases were higher than new TB cases. A similar finding was reported from Central Ethiopia [17]. A former study from Northern Ethiopia indicated that patients with a previous exposure to TB drugs had 6.4 times higher risk of developing multi-drug resistant TB (MDR-TB) than newly diagnosed TB cases [36]. The prevalence of MDR-TB among retreatment cases in Ethiopia varied from $12 \%$ to $18.5 \%$ [36] [37]. The high failure and death rates among retreatment cases in this study might be linked to high prevalence rate of MDR-TB among this group of patient [38]. Strengthening the capacity of TB diagnostic facilities for early detection and management of MDR-TB cases is important.

In our study, despite the high treatment success rate of new PTB+ ve cases, the overall cure rate was $72.1 \%$, which is lower than previous cure rate reports of 85.5\% from Northern Ethiopia [12] and 81.1\% in North West Ethiopia [31]. Sputum smear examination at two, five and seven months is recommended as part of anti-TB 
treatment follow up. Nearly 30\% of PTB+ cases in this study completed their treatment without confirmed bacteriology result. In addition, for an average of more than $30 \%$ of PTB + patients, the follow-up sputum smear examination result was not documented at two, five and seven months. This indicates the gap in appropriately following up PTB+ cases. Failure to act at the recommended time periods for follow up sputum smear examination results may increase the risk of failure or relapse among patients who are still smear-positive. This period must be monitored very closely during supervision. Further qualitative study is also needed to explore the reasons for not appropriately performing the follow up sputum smear result in a timely manner.

In this study, a high proportion of EPTB cases were observed compared to PTB patients. Similar findings were reported from previous studies in Ethiopia [13] [15] [31]. Evidence also indicates that less proportion of EPTB cases compared to other forms of TB were observed in other studies conducted in Ethiopia [14] [16]. EPTB is more common in HIV infected patients [13] [15]. In our study, 32.8\% of HIV infected patients were EPTB cases. Further research is warranted to investigate the reasons for the very high proportion of EPTB cases in the study zone.

Retreatment and HIV co-infected patients were independently associated with unfavorable treatment outcome. Similar findings were previously reported [12] [17]. The finding indicates that retreatment and HIV co-infected TB patients need strict follow up throughout their treatment period.

We observed missing data for patients' socio demographic and clinical information, follow-up sputum examination result and treatment outcome. This problem should be addressed by taking measures that improve the TB recording and reporting system. Continuous refresher training of health personnel on health management and information system, supportive supervision and regular monitoring and evaluation of the TB control program in the study zone are important measures.

Our study shares the inherent limitation of retrospective study and may be subjected to random error and selection bias. The unit TB registers we reviewed lack full list of variables that may have association with treatment outcome. Data with unknown treatment outcome were excluded from the treatment outcome analysis. However, as we had large cohort of TB cases in our sample and included all districts and town administrations in the study zone, the effect of selection bias may be minimized.

\section{Conclusion}

Tuberculosis case notification rates showed a decreasing trend between 2007 and 2012. The treatment success rate exceeded the $90 \%$ treatment success rate target as set by the WHO and was consistently high over the study years. Special attention is required for patients with high risk of unsuccessful treatment outcome. Therefore, retreatment and HIV positives cases need strict follow up throughout their treatment period. Supportive supervision should be strengthened to maintain the high treatment success rate, and closely monitor time of follow-up sputum smear examinations. The health management information system at health facility level must be improved so that complete data for each patient is recorded in the unit TB registers.

\section{Acknowledgements}

We would like to thank the University of Oslo for funding this study. We also would like to thank the Amhara Regional State Health Bureau, the West Gojjam Zone Health Department, the Districts and Town administrations health offices for facilitating this study. We would like also to extend our thanks to all the data collectors and the heads of health facilities where this study was conducted.

\section{Competing Interests}

The authors declare that they have no competing interests.

\section{References}

[1] World Health Organization (2015) Global Tuberculosis Report 2015, Geneva.

[2] Federal Ministry of Health Ethiopia (2011) First Ethiopian National Population Based Tuberculosis Prevalence Survey. FMOH, Addis Ababa.

[3] Federal Ministry of Health Ethiopia (2014) Ethiopian Public Health Institute Implementation Guideline for Gene Xpert MTB/RIF Assay in Ethiopia. FMOH, Addis Ababa. 
[4] Federal Ministry of Health Ethiopia (2008) Tuberculosis, Leprosy and TB/HIV Prevention and Control Program Manual. FMOH, Addis Ababa.

[5] Tadesse, T., Demissie, M., Berhane, Y., Kebede, Y. and Abebe, M. (2011) Two-Thirds of Smear-Positive Tuberculosis Cases in the Community Were Undiagnosed in Northwest Ethiopia: Population Based Cross-Sectional Study. PLoS ONE, 6, e28258. http://dx.doi.org/10.1371/journal.pone.0028258

[6] Yimer, S., Holm-Hansen, C., Yimaldu, T. and Bjune, G. (2009) Evaluating an Active Case-Finding Strategy to Identify Smear-Positive Tuberculosis in Rural Ethiopia. International Journal of Tuberculosis and Lung Disease, 13, 13991404.

[7] Berhe, G., Enqueselassie, F., Hailu, E., Mekonnen, W., Teklu, T., Gebretsadik, A., et al. (2013) Population-Based Prevalence Survey of Tuberculosis in the Tigray Region of Ethiopia. BMC Infectious Diseases, 13, 448. http://dx.doi.org/10.1186/1471-2334-13-448

[8] Deribew, A., Abebe, G., Apers, L., Abdissa, A., Deribe, F., Woldemichael, K., et al.( 2012) Prevalence of Pulmonary TB and Spoligotype Pattern of Mycobacterium tuberculosis among TB Suspects in a Rural Community in Southwest Ethiopia. BMC Infectious Diseases, 12, 54. http://dx.doi.org/10.1186/1471-2334-12-54

[9] Yassin, M.A., Datiko, D.G., Tulloch, O., Markos, P., Aschalew, M., Shargie, E.B., et al. (2013) Innovative Community-Based Approaches Doubled Tuberculosis Case Notification and Improve Treatment Outcome in Southern Ethiopia. PLoS ONE, 8, 63174. http://dx.doi.org/10.1371/journal.pone.0063174

[10] World Health Organization (1994) Tuberculosis Programme Framework for Effective Tuberculosis Control. http://apps.who.int/iris/bitstream/10665/58717/1/WHO_TB_94.179.PDF

[11] Vasankari, T., Holmström, P., Ollgren, J., Liippo, K., Kokki, M. and Ruutu, P. (2007) Risk Factors for Poor Tuberculosis Treatment Outcome in Finland: A Cohort Study. BMC Public Health, 7, 291. http://dx.doi.org/10.1186/1471-2458-7-291

[12] Berhe, G., Enquselassie, F. and Aseffa, A. (2012) Treatment Outcome of Smear-Positive Pulmonary Tuberculosis Patients in Tigray Region, Northern Ethiopia. BMC Public Health, 12, 537. http://dx.doi.org/10.1186/1471-2458-12-537

[13] Getahun, B., Ameni, G., Medhin, G. and Biadgilign, S. (2013) Treatment Outcome of Tuberculosis Patients under Directly Observed Treatment in Addis Ababa, Ethiopia. The Brazilian Journal of Infectious Disease, 17, 521-528. http://dx.doi.org/10.1016/j.bjid.2012.12.010

[14] Sisay, S., Mengistu, B., Erku, W. and Woldeyohannes, D. (2014) Directly Observed Treatment Short-Course (DOTS) for Tuberculosis Control Program in Gambella Regional State, Ethiopia: Ten Years Experience. BMC Research Notes, 7, 44. http://dx.doi.org/10.1186/1756-0500-7-44

[15] Beza, M.G., Wubie, M.T., Teferi, M.D., Getahun, Y.S., Bogale, S.M. and Tefera, S.B. (2013) A Five Years Tuberculosis Treatment Outcome at Kolla Diba Health Center, Dembia District, Northwest Ethiopia. A Retrospective CrossSectional Analysis. Infectious Diseases \& Therapy, 1, 101.

[16] Tessema, B., Muche, A., Bekele, A., Reissig, D., Emmrich, F. and Sack, U. (2009) Treatment Outcome of Tuberculosis Patients at Gondar University Teaching Hospital, Northwest Ethiopia. A Five-Year Retrospective Study. BMC Public Health, 9, 371. http://dx.doi.org/10.1186/1471-2458-9-371

[17] Hamusse, S.D., Demissie, M., Teshome, D. and Lindtjørn, B. (2014) Fifteen-Year Trend in Treatment Outcomes among Patients with Pulmonary Smear-Positive Tuberculosis and Its Determinants in Arsi Zone, Central Ethiopia. Global Health Action, 7, 25382. http://dx.doi.org/10.3402/gha.v7.25382

[18] Muñoz-Sellart, M., Cuevas, L.E., Tumato, M., Merid, Y. and Yassin, M.A. (2010) Factors Associated with Poor Tuberculosis Treatment Outcome in the Southern Region of Ethiopia. International Journal of Tuberculosis and Lung Disease, 14, 973-979.

[19] Biadglegne, F., Anagaw, B., Debebe, T., Anagaw, B., Tesfaye, W., Tessema, B., et al. (2013) A Retrospective Study on the Outcomes of Tuberculosis Treatment in Felege Hiwot Referral Hospital, Northwest Ethiopia. International Journal of Medicine and Medical Sciences, 5, 85-91.

[20] Amhara Regional State Health Bureau (2009) Fifth National TB Research Conference, Jimma Town, 21-23 October 2009. http://www.etharc.org/resources/download/finish/66/359

[21] Central Statistics Authority of Ethiopia (2007) Summary and Statistical Report of the Population and Housing Census 2008. Addis Ababa. Central Statistic Authority of Ethiopia.

[22] Yimer, S., Holm-Hansen, C., Yimaldu, T. and Bjune, G. (2009) Health Care Seeking among Pulmonary Tuberculosis Suspects and Patients in Rural Ethiopia: A Community-Based Study. BMC Public Health, 9, 454. http://dx.doi.org/10.1186/1471-2458-9-454

[23] Hamusse, S.D., Demissie, M. and Lindtjørn, B. (2014) Trends in TB Case Notification over Fifteen Years: The Case Notification of 25 Districts of Arsi Zone of Oromia Regional State, Central Ethiopia. BMC Public Health, 14, 304. http://dx.doi.org/10.1186/1471-2458-14-304 
[24] Ministry of Health of Ethiopia (2007) Single-Point HIV Prevalence Estimate 2007, Addis Ababa.

[25] Institutionalization Plan for Mentoring Program (2013-2014) Amhara Regional Health Bureau Mentoring Transition Road Map. Bahir Dar, Ethiopia.

[26] Ethiopia HIV/AIDS Care and Support Program (2008) Semiannual Progress Report. Ethiopia HIV/AIDS Care and Support Program; Management Sciences for Health, Cambridge.

[27] Zachariah, R., Bemelmans, M., Akesson, A., Gomani, P., Phiri, K., Isake, B., et al. (2011) Reduced Tuberculosis Case Notification Associated with Scaling up Antiretroviral Treatment in Rural Malawi. International Journal of Tuberculosis and Lung Disease, 15, 933-937. http://dx.doi.org/10.5588/ijtld.10.0666

[28] Haumba, S., Dlamini, T., Calnan, M., Ghazaryan, V., Smith-Arthur, A.E., Preko, P., et al. (2015) Declining Tuberculosis Notification Trend Associated with Strengthened TB and Expanded HIV Care in Swaziland. PHA, 5, 103-105. http://dx.doi.org/10.5588/pha.15.0008

[29] World Health Organization (2012) Global Tuberculosis Report 2012, Geneva.

[30] Tadesse, S. and Tadesse, T. (2014) Treatment Success Rate of Tuberculosis Patients in Dabat, Northwest Ethiopia. Health, 6, 306-310. http://dx.doi.org/10.4236/health.2014.65044

[31] Tesfahuneygn, G., Medhin, G. and Legesse, M. (2015) Adherence to Anti-Tuberculosis Treatment and Treatment Outcomes among Tuberculosis Patients in Alamata District, Northeast Ethiopia. BMC Research Notes, 8, 503. http://dx.doi.org/10.1186/s13104-015-1452-X

[32] Endris, M., Moges, F., Belyhun, Y., Woldehana, E., Esmael, A. and Unakal, C. (2014) Treatment Outcome of Tuberculosis Patients at Enfraz Health Center, Northwest Ethiopia: A Five-Year Retrospective Study. Tuberculosis Research and Treatment, 2014, Article ID: 726193. http://dx.doi.org/10.1155/2014/726193

[33] Ministry of Health of Ethiopia (2012) Guidelines for Clinical and Programmatic Management of TB, Leprosy and TB/HIV in Ethiopia. Addis Ababa.

[34] Dangisso, M.H., Datiko, D.G. and Lindtjørn, B. (2014) Trends of Tuberculosis Case Notification and Treatment Outcomes in the Sidama Zone, Southern Ethiopia: Ten-Year Retrospective Trend Analysis in Urban-Rural Settings. PLoS ONE, 9, e114225. http://dx.doi.org/10.1371/journal.pone.0114225

[35] Vasankari, T., Holmström, P., Ollgren, J., Liippo, K., Kokki, M. and Ruutu, P. (2007) Risk Factors for Poor Tuberculosis Treatment Outcome in Finland: A Cohort Study. BMC Public Health, 7, 291. http://dx.doi.org/10.1186/1471-2458-7-291

[36] Esmael, A., Ali, I., Agonafir, M., Endris, M., Getahun, M., Yaregal, Z., et al. (2014) Drug Resistance Pattern of Mycobacterium tuberculosis in Eastern Amhara Regional State, Ethiopia. Journal of Microbial \& Biochemical Technology, 6, 75-79. http://dx.doi.org/10.4172/1948-5948.1000125

[37] World Health Organization (2009) Global Tuberculosis Control, 2009: Epidemiology, Strategy, Financing. WHO, Geneva.

[38] World Health Organization (2008) Guidelines for the Programmatic Management of Drug-Resistant Tuberculosis. WHO, Geneva. 